\title{
STAT3 Mediates the Differential Effects of Oncostatin M and TNF $\alpha$ on RA Synovial Fibroblast and Endothelial Cell Function
}

\author{
Megan M. Hanlon 1, Tatsiana Rakovich 1, Clare C. Cunningham ", Sharon Ansboro ${ }^{1}$, \\ Douglas J. Veale ${ }^{2}$, Ursula Fearon ${ }^{1,2 * t}$ and Trudy McGarry ${ }^{1,2+}$ \\ ${ }^{1}$ Molecular Rheumatology, Trinity Biomedical Sciences Institute, TCD, Dublin, Ireland, ${ }^{2}$ Centre for Arthritis and Rheumatic \\ Diseases, St. Vincent's University Hospital, UCD, Dublin, Ireland
}

OPEN ACCESS

Edited by:

Massimo Gadina

National Institute of Arthritis and Musculoskeletal and Skin Diseases (NIAMS), United States

Reviewed by:

Kiyoshi Hirahara,

Chiba University, Japan Amy Naylor

University of Birmingham, United Kingdom

*Correspondence: Ursula Fearon fearonu@tcd.ie

† Joint senior authors

Specialty section:

This article was submitted to Inflammation,

a section of the journal

Frontiers in Immunology

Received: 24 May 2019 Accepted: 14 August 2019 Published: 28 August 2019

Citation:

Hanlon MM, Rakovich T, Cunningham CC, Ansboro $S$, Veale DJ, Fearon U and McGarry T (2019) STAT3 Mediates the Differential Effects of Oncostatin M and TNF $\alpha$ on RA Synovial Fibroblast and Endothelial

Cell Function.

Front. Immunol. 10:2056 doi: 10.3389/fimmu.2019.02056
Objectives: Oncostatin M (OSM), a pleiotropic cytokine and a member of the gp130/IL-6 cytokine family, has been implicated in the pathogenesis of autoimmune diseases. Here we investigate the mechanisms by which its synergistic interactions with TNF $\alpha$ regulate the cellular bioenergetics and invasive function of synovial cells from patients with Rheumatoid Arthritis.

Methods: Primary RA synovial fibroblasts (RAFLS) and human umbilical vein endothelial cells (HUVEC) were cultured with OSM alone or in combination with TNF $\alpha$. Pro-inflammatory cytokines, angiogenic growth factors and adhesion molecules were quantified by real-time PCR and ELISA. Invasion, angiogenesis and cellular adhesion were quantified by Transwell invasion chambers, Matrigel tube formation assays, and adhesion binding assays. Cellular bioenergetics was assessed using the Seahorse XFe96 Analyser. Key metabolic genes (GLUT-1, HK2, PFKFB3, HIF1 $\alpha$, LDHA, PKM2) and transcription factor STAT3 were measured using real-time PCR and western blot.

Results: OSM differentially regulates pro-inflammatory mediators in RAFLS and HUVEC, with IL-6, MCP-1, ICAM-1, and VEGF all significantly induced, in contrast to the observed inhibition of IL-8 and GRO $\alpha$, with opposing effects observed for VCAM-1 depending on cell type. Functionally, OSM significantly induced angiogenic network formation, adhesion, and invasive mechanisms. This was accompanied by a change in the cellular bioenergetic profile of the cells, where OSM significantly increased the ECAR/OCR ratio in favor of glycolysis, paralleled by induction of the glucose transporter GLUT-1 and key glycolytic enzymes (HK2, PFKFB3, HIF1 $\alpha$ ). OSM synergizes with TNF $\alpha$ to differentially regulate pro-inflammatory mechanisms in RAFLS and HUVEC. Interestingly, OSM differentially synergizes with TNF $\alpha$ to regulate metabolic reprogramming, where induction of glycolytic activity with concomitant attenuation of mitochondrial respiration and ATP activity was demonstrated in RAFLS but not in HUVEC. Finally, we identified a mechanism, whereby the combination of OSM with TNF $\alpha$ induces transcriptional activity of STAT3 only in RAFLS, with no effect observed in HUVEC. 
Conclusion: STAT3 mediates the differential effects of OSM and TNF $\alpha$ on RAFLS and EC function. Targeting OSM or downstream signaling pathways may lead to new potential therapeutic or adjuvant strategies, particularly for those patients who have sub-optimal responses to TNFi.

Keywords: rheumatoid arthritis, cellular bioenergetics, pro-inflammatory cytokines, JAK-STAT signaling, synovial fibroblasts

\section{INTRODUCTION}

Rheumatoid arthritis (RA) is a chronic autoimmune disease characterized by synovial hyperplasia and degradation of articular cartilage and bone, ultimately leading to irreversible disability. Although the initiating trigger for RA is not known, angiogenesis is one of the earliest events in the pathogenesis of this disease. Sprouting angiogenesis allows for a self-perpetuating influx of immune cells into the synovial joint, resulting in expansion of the synovial tissue into an aggressive tumor-like pannus (1). Despite this increased vascular supply, studies have demonstrated that the synovial joint is profoundly hypoxic (2). This is due to the highly dysfunctional and immature nature of the vasculature resulting in abnormal blood flow supplying inadequate nutrients and oxygen to the expanding synovium. Thus, the increasing metabolic turnover of the pannus outpaces vascular supply, rendering the inflamed synovium hypoxic (3-6).

The importance of metabolism in regulating synovial inflammation has recently emerged with many studies indicating that immune and stromal cells undergo a bioenergetic switch to a highly metabolically active state in order to meet the energy demands of the expanding synovium $(7,8)$. Indeed, the metabolic milieu of the inflamed joint reflects the chronically active state of immune and stromal cells, with elevated lactate levels and reduced glucose observed in RA synovial fluid, along with increased glycolytic enzyme activity and accumulation of succinate in synovial fluid and tissue (913). Recent studies have shown that treatment with glycolytic inhibitors dampens cytokine production, invasive mechanisms, and key transcriptional regulators in various synovial cells while also improving disease severity in animal models of arthritis $(9,14,15)$.

The cytokine Oncostatin M (OSM) is highly expressed in the RA joint, and shares a common receptor signal subunit (gp-130) with IL-6-type cytokines (16). Produced mainly by macrophages, neutrophils and activated T-cells, OSM signals via the Janus Kinase (JAK) family of receptor-associated tyrosine kinases and is associated with the activation of STAT3 (1719). Increased expression of OSM is associated with a plethora of pathologies including atherosclerosis, psoriasis, and many cancers $(20,21)$. Most recently, OSM has been shown to play a role in inflammatory bowel disease (IBD) with a study demonstrating heightened expression of OSM and its receptor in the inflamed IBD intestine, correlating with disease severity (22).

In the context of RA, overexpression of OSM in synovial fluid and tissue has been observed with levels correlating with joint inflammation (23). Collectively, studies have demonstrated that
OSM plays a critical role in RAFLS activation, promotion of angiogenesis, adhesion molecules and chemokines from RAFLS, altering the matrix metalloproteinases (MMP)/tissue inhibitor of matrix metalloproteinases (TIMP) ratio and inducing RANKL in RAFLS and chondrocytes in favor of joint destruction (21, $24,25)$. Blocking OSM in a collagen-induced arthritis mouse model improves joint inflammation and cartilage damage (26). Furthermore, recent studies have demonstrated that inhibition of OSM-induced RAFLS pro-inflammatory mechanisms and cartilage degradation are rescued in the presence of JAK-STAT inhibitors $(27,28)$, effects that are, in part, mediated by a switch in the metabolic profile of the cell (29). Conversely, OSM is a pleiotropic cytokine often displaying divergent effects with both pro- and anti-inflammatory effects depending on the cell type and microenvironment. Previous studies have shown that OSM can inhibit IL-1-induced IL- 8 and granulocyte macrophage colony stimulating factor (GM-CSF) and promote TIMP expression in RAFLS $(24,30)$. OSM inhibits TNF $\alpha$ and IL-17A-induced TIMP-1 while potentiating IL-1 $\beta$-induced TIMP-1 expression in RAFLS $(24,31)$. More recently, studies have demonstrated that OSM can inhibit Th17 differentiation in mouse models of arthritis through reciprocal regulation of SOCS3, STAT3, and STAT5 (32). Therefore, the role of OSM in RA disease pathology is complex, depending largely on cell type and microenvironment.

Given the pivotal role of metabolism in regulating synovial inflammation, in this study we examined the effect of OSM on pro-inflammatory, angiogenic, and bioenergetic mechanisms in RAFLS and HUVEC. Furthermore, we investigated the relationship between OSM and the major pro-inflammatory cytokine; tumor necrosis factor $\alpha$ $(\mathrm{TNF} \alpha)$, a central player in inflammation and destruction in the RA joint.

\section{MATERIALS AND METHODS}

\section{Patient Recruitment and Arthroscopy}

RA patients were recruited from the Rheumatology Department, St. Vincent's University Hospital. All patients gave fully informed written consent approved by the St. Vincent's University Hospital, Ethics and Medical Research Committee and research was performed in accordance with the Declaration of Helsinki. Synovial tissue biopsies were obtained at arthroscopy under local anesthetic using a Wolf $2.7 \mathrm{~mm}$ telescope (Wolf-Germany) as previously described (2). Biopsies were utilized for isolation of primary RA synovial fibroblasts (RAFLS). 


\section{Isolation of Primary Fibroblasts}

RA synovial biopsies were digested with $1 \mathrm{mg} / \mathrm{ml}$ collagenase type 1 (Worthington Biochemical, Freehold, NJ, USA) in RPMI-1640 (Gibco-BRL, Paisley, UK) for $4 \mathrm{~h}$ at $37^{\circ} \mathrm{C}$ in humidified air with $5 \% \mathrm{CO}_{2}$. Dissociated cells were grown to confluence in RPMI 1640, 10\% FCS (Gibco-BRL), $10 \mathrm{ml}$ of $1 \mathrm{mmol} / \mathrm{l} \mathrm{HEPES} \mathrm{(Gibco-}$ BRL), penicillin (100 units/ml; Bioscience), streptomycin (100 units $/ \mathrm{ml}$; Bioscience) and fungizone $(0.25 \mu \mathrm{g} / \mathrm{ml}$; Bioscience) before passaging. Cells were used between passages 3-8.

\section{Culture of HUVEC}

Human umbilical vein endothelial cells (HUVEC) (ATCC, Manassas, USA) were grown to confluence in endothelial cell basal media (MCDB-131, Gibco) supplemented with LGlutamine (20 $\mathrm{ml}$ of $100 \mathrm{X}$ solution), Hydrocortisone $(0.6 \mu \mathrm{g} / \mathrm{ml})$, hEGF $(0.01 \mu \mathrm{g} / \mathrm{ml})$, Penicillin/Streptomycin (100 units $/ \mathrm{ml}$; Biosciences), Fungizone $(0.25 \mu \mathrm{g} / \mathrm{ml}$; Biosciences) and $15 \%$ FCS (Gibco-BRL).

\section{Cytokine and Chemokine Measurements}

To assess the effects of OSM on pro-inflammatory mediators, RAFLS/HUVEC were seeded in 48-well plates at a density of 3 $\times 10^{5}$ and allowed to attach overnight. Cells were incubated in serum-free RPMI-1640 or MCDB-131 for $24 \mathrm{~h}$ and subsequently stimulated with OSM $(10 \mathrm{ng} / \mathrm{ml})$. For synergy experiments, cells were also incubated in the presence or absence of TNF $\alpha(0.01,0.1$, $1 \mathrm{ng} / \mathrm{ml})$. Supernatants were harvested and levels of IL-6, MCP1, IL-8, RANTES, and GRO $\alpha$ were measured by specific ELISA (MCP-1: eBiosciences, USA, IL-6, IL-8, RANTES, GRO $\alpha$; R\&D systems, UK) according to manufacturer's conditions.

\section{Transwell Invasion Assay}

Biocoat Matrigel $^{\mathrm{TM}}$ Invasion Chambers (Becton Dickinson, UK) were used to assess RAFLS/HUVEC invasion. Cells were seeded at a density of either $3.5 \times 10^{4}$ (RAFLS) or $2.5 \times 10^{4}$ (HUVEC) cells per well in the migration chamber on $8 \mu \mathrm{m}$ membranes precoated with matrigel. Cells were incubated with OSM $(10 \mathrm{ng} / \mathrm{ml})$ for $24 \mathrm{~h}$ (HUVEC) or $48 \mathrm{~h}$ (RAFLS). Non-migrating cells were removed from the upper surface by gentle scrubbing. Migrating cells attached to the lower membrane were fixed with $4 \%$ paraformaldehyde and stained with $0.1 \%$ crystal violet. Cells from five random high power fields for each well were counted to assess the average number of invading cells.

\section{HUVEC Tube Formation}

Matrigel (50 $\mu \mathrm{l}$; BD Biosciences, San Jose, CA, USA) was plated in 96-well culture plates after thawing on ice and allowed to polymerise for $30 \mathrm{~min}$ at $37^{\circ} \mathrm{C}$ in humidified air with $5 \% \mathrm{CO}_{2}$. $2 \times 10^{4}$ cells in supplemented MCDB-131 was added to each well and cells were stimulated with OSM $(10 \mathrm{ng} / \mathrm{ml})$ on control medium for $24 \mathrm{~h}$. EC tubule formation was then assessed using phase-contrast microscopy. Cells were quantified by counting the number of connecting branches formed from five random high power fields as previously described (24).

\section{Adhesion Assay}

RAFLS/HUVEC were grown to confluence in 24-well plates, incubated in serum-free RPMI-1640 or MCDB-131 for $24 \mathrm{~h}$ and subsequently stimulated with OSM $(10 \mathrm{ng} / \mathrm{ml})$ for a further $24 \mathrm{~h}$. PBMC from healthy donors were isolated by density gradient centrifugation (Lymphoprep; Stemcell Technologies) according to the manufacturer's recommendations. PBMC were then resuspended in MCDB-131. $7.5 \times 10^{4} \mathrm{PBMC}$ were added to each well containing RAFLS/HUVEC and incubated at $37^{\circ} \mathrm{C}$ with $5 \% \mathrm{CO}_{2}$ for $1 \mathrm{~h}$. After the incubation time, supernatants were removed and wells were washed with PBS. Semi-quantification was performed by counting adherent PBMCs as viewed under phase-contrast microscopy (Leica, Germany) at $10 \times$ magnification. Cells from five random high power fields for each well were counted to assess the average number of adherent cells.

\section{mRNA Extraction and cDNA Synthesis}

To assess the effects of OSM on specific genes, RAFLS/HUVEC were seeded into 6-well plates and allowed to grow to confluence. Cells were incubated in serum-free RPMI-1640 or MCDB-131 for $24 \mathrm{~h}$ and subsequently stimulated with OSM $(10 \mathrm{ng} / \mathrm{ml})$. For synergy experiments, cells were also incubated in the presence or absence of TNF $\alpha(1 \mathrm{ng} / \mathrm{ml})$. Total RNA was isolated using the miRNeasy Mini Kit (Qiagen, Germany) according to the manufacturer's protocol. The integrity of RNA samples were assessed using a bioanalyzer (Agilent, CA, USA). Samples with a $260: 280 \mathrm{~nm}$ ratio of 1.8 and above and an RNA integrity number between 7 and 10 were used in subsequent experiments. Isolated RNA was stored at $-80^{\circ} \mathrm{C}$. Total RNA (100 ng) was reverse transcribed to cDNA using a high capacity cDNA reverse transcription kit (Applied Biosystems, Cheshire, UK) and stored at $-20^{\circ} \mathrm{C}$ until further use.

\section{RT-PCR Analysis}

Gene expression data were quantified by RT-PCR using the Quant Studio 5 Thermal Cycler (Applied Biosystem, Lewes, UK). Reaction mixtures contained $1 \mu \mathrm{l}$ of cDNA, SYBR green I PCR mastermix (Applied Biosystems) and target mRNA specific primer pairs as follows: VEGF for $5^{\prime}$ GCAGAATCAT CACGAAGTGGTG $3^{\prime}$ VEGF rev $5^{\prime}$ TCTCGATTGGATG GCAGTAGCT 3', VCAM-1 for 5' GTA AAA GAA TTG CAA GTC TAC ATATCAC 3', VCAM-1 rev 5' GATGGATTCAC AGAAATAACTGTATTC $3^{\prime}$, ICAM-1 for $5^{\prime}$ AACCAGAGC CAGGAGACACTG 3', ICAM-1 rev 5' GCGCCGGAAAGCTG TAGATG $3^{\prime}$, HIF1 $\alpha$ for $5^{\prime}$ GAAACTTCTGGATGCTGGT GATTT 3', HIF1 $\alpha$ rev 5' GCAATTCATCTGTGCTTTCATG TCA $3^{\prime}$, HK2 for $5^{\prime}$ TTCTTGTCTCAG ATTGAGAGTGAC 3', HK2 rev 5' TTGCAGGATGGCTCGGACTTG 3', LDHA for $5^{\prime}$ ATGGAGATTCCAGTGTGCCTGT 3', LDHA rev 5' CAGAGAGACACCAGCAACATTC $3^{\prime}$, GLUT1 for $5^{\prime}$ CTTCCAGTATGTGGAGCAACTGT, GLUT1 rev $5^{\prime}$ GCAC AGTGAAGATGATGAAGACG $3^{\prime}$, PFKFB3 for 5' ACCAA AGATCACCCACGGATGT 3', PFKFB3 rev $5^{\prime}$ AGCGAGTGCA GAATGGACACAA 3', PKM2 for 5' ATTATTTGAGGAACT CCGCCG 3', PKM2 rev 5 'ATTCCGGGTCACAGCAATGAT 3', STAT3 for $5^{\prime}$ TTCACTTGGGTGGAGAAG $3^{\prime}$ and STAT3 rev $5^{\prime}$ CGGACTGGATCTGGGTCT 3'. Samples lacking multiscribe reverse transcriptase formed negative controls to ensure target-specific quantification. Data were analyzed using the 
comparative threshold cycle $(\mathrm{Ct})$ method with normalization to the expression of RPLPO (for $5^{\prime}$ GCGTCCTCGTGGAAGTGA CATCG 3', rev 5' TCAGGGATTGCCACGCAGGG $3^{\prime}$ ) and HPRT1 (for 5' ATGGACAGGACTGAACGTCTTG 3', rev 5' GGCTACAATGTGATGGCCTC 3') as endogenous controls.

\section{Cellular Bioenergetic Function Analysis}

Oxygen consumption rate (OCR) and extracellular acidification rate (ECAR), reflecting oxidative phosphorylation and glycolysis, respectively, were measured using the SeahorseXFe96 analyzer (Seahorse Biosciences). RAFLS/HUVEC were seeded at 15,000 cells per well in a 96-well cell culture $\mathrm{XFe}$ microplate (Seahorse Biosciences) and allowed to adhere overnight. Following this, cells were then cultured with OSM $(10 \mathrm{ng} / \mathrm{ml})$ for $3 \mathrm{~h}$. For synergy experiments, cells were also incubated in the presence or absence of $\mathrm{TNF} \alpha(1 \mathrm{ng} / \mathrm{ml})$ for $3 \mathrm{~h}$. Cells were then washed with assay medium (unbuffered DMEM supplemented with $10 \mathrm{mM}$ glucose, $\mathrm{pH}-7.4)$ before incubation with assay medium for $30 \mathrm{~min}$ at $37^{\circ} \mathrm{C}$ in a non- $\mathrm{CO}_{2}$ incubator. Basal oxidative phosphorylation/glycolysis was calculated by the average of three baseline OCR/ECAR measurements, respectively, obtained before injection of specific metabolic inhibitors; oligomycin (ATP-synthase-inhibitor) $(2 \mu \mathrm{g} / \mathrm{ml}$; Seahorse Biosciences, UK) trifluorocarbonylcyanide phenylhydrazone (FCCP) (mitochondrial uncoupler) (5 $\mu \mathrm{M}$; Seahorse Biosciences) and antimycin A (complex-III inhibitor) $(2 \mu \mathrm{M}$; Seahorse Biosciences). Oligomycin was injected to evaluate both the maximal glycolytic rate and ATP synthesis, determined by subtracting the amount of respiration left after oligomycin injection from baseline OCR. FCCP was injected to evaluate the maximal respiratory capacity (average of three measurements following injection). Maximal respiratory capacity was determined by subtracting baseline OCR from FCCP-induced OCR and the respiratory reserve (baseline OCR subtracted from maximal respiratory capacity).

\section{Protein Isolation and Western Blotting Analysis}

RAFLS/HUVEC were grown to confluence in 6-well plates. Once confluent, cells were incubated in serum-free RPMI-1640 or MCDB-131 for $24 \mathrm{~h}$ and subsequently stimulated with OSM $(10 \mathrm{ng} / \mathrm{ml})$. For synergy experiments, cells were also incubated in the presence or absence of $\mathrm{TNF} \alpha(1 \mathrm{ng} / \mathrm{ml})$. Cells were trypsinized and collected prior to cell lysis. Ice-cold RIPA (Radio-Immunoprecipitation Assay) buffer (Sigma) containing $10 \mu \mathrm{g} / \mathrm{ml}$ phosphatase inhibitor cocktail and $10 \mu \mathrm{g} / \mathrm{ml}$ protease inhibitor cocktail (Sigma) was used to extract protein from HUVEC/RAFLS. Measurement of protein concentration was performed using a BCA assay (Pierce Chemical Co, Rockford, IL, USA). Protein (2-5 $\mu \mathrm{g}$ ) was resolved by SDS-PAGE (5\% stacking, $10 \%$ resolving), gels were then transferred onto nitrocellulose membranes (Amersham Biosciences, Buckinghamshire, UK) prior to $1 \mathrm{~h}$ blocking in wash buffer containing $5 \%$ non-fat milk with gentle agitation at room temperature. Membranes were incubated with mouse monoclonal anti-HK2 (Novus Biologicals, USA), rabbit monoclonal anti-PFKFB3 (Abcam,
UK), rabbit polyclonal anti-GLUT-1 (Abcam), anti-pSTAT3, and anti-total STAT3 (Cell-Signaling Technology, UK) diluted in $5 \%$ non-fat milk containing $0.1 \%$ Tween 20 at $4{ }^{\circ} \mathrm{C}$ overnight with gentle agitation. $\beta$-actin $(1: 5,000$, Sigma) was used as a loading control. Following three $15 \mathrm{~min}$ washes, membranes were incubated with appropriate horseradish peroxidase-conjugated secondary antibodies $(1: 5,000)$ for $3 \mathrm{~h}$ at room temperature. The signal was detected using SuperSignal ${ }^{\circledR}$ West Pico Chemiluminescent Substrate (Amersham Biosciences). Band densities were imaged using the ChemiDoc MP Imaging System (Bio-Rad, USA).

\section{Statistical Analysis}

Statistical analyses were performed using Prism 5 software. Wilcoxon Signed Rank test or Mann Whitney was used for analysis of non-parametric data. Student $t$-test was used for parametric data. $P$-values of $<0.05\left({ }^{*} p<0.05\right)$ were determined as statistically significant.

\section{RESULTS}

\section{OSM Differentially Regulates Cytokine and Chemokine Secretion in RAFLS and HUVEC}

To initially assess the effect of OSM on pro-inflammatory mechanisms, a range of pro-inflammatory mediators were measured in RAFLS and HUVEC (Figure 1). OSM significantly induced expression of IL-6, MCP-1, and ICAM-1 in RAFLS and HUVEC (all $p<0.05$ ) (Figures 1A,B), in addition to the main angiogenic growth factor VEGF $(p<0.05)$ (Figures 1A,B). In contrast, OSM inhibited the secretion of IL-8 $(p<0.05)$ and GRO $\alpha$ from both RAFLS and HUVEC (Figures 1A,B), with no effect observed for RANTES (Figures 1A,B). Interestingly, OSM induced VCAM-1 in RAFLS (Figure 1A), but inhibited VCAM-1 expression in HUVEC $(p<0.05)$ (Figure 1B). This data demonstrates the differential effects of OSM, displaying both pro-and anti-inflammatory effects in different cell types, but also within the same cell type.

\section{OSM Promotes Adhesion, Invasive, and Tube Formation Mechanisms in RAFLS and HUVEC}

To further investigate the role of OSM we next assessed cellular function by performing adhesion, invasion and angiogenic assays. OSM stimulation significantly increased the adhesive capacity of RAFLS and HUVEC, resulting in a significant increase in PBMC attachment to the cell surface of RAFLS and HUVEC (Figures 1Ci,Di). Next, to assess the effects of OSM on RAFLS and HUVEC invasion, Transwell Matrigel $^{\mathrm{TM}}$ invasion chambers were utilized. Representative images of increased RAFLS and HUVEC invasion following OSM stimulation are shown in Figures 1Cii,Dii. Quantitatively, RAFLS and HUVEC invasion were significantly induced by OSM compared to basal control (both $p<0.05$ ) (Figures 1Cii,Dii). Finally, representative images of HUVEC tube formation are shown in Figure 1Diii, demonstrating a significant increase 
A
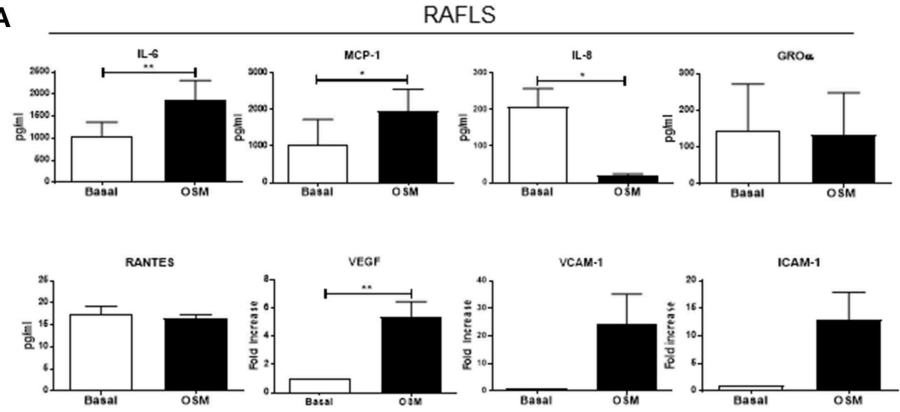

B
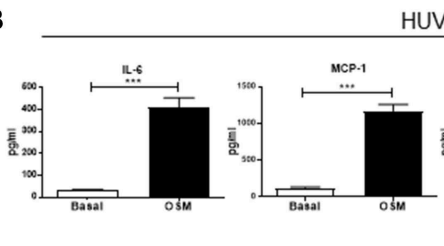

HUVEC
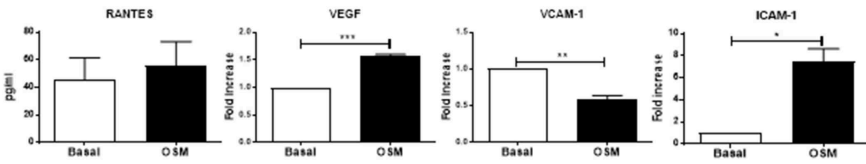

C

(i)
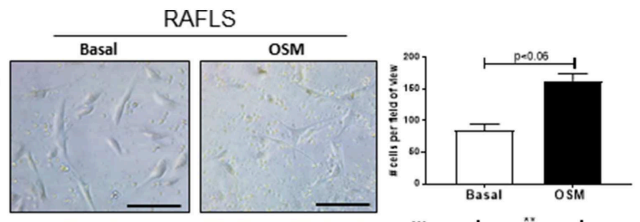

(ii)
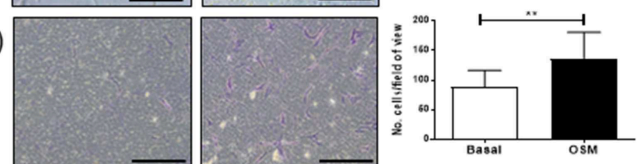

D

(i)

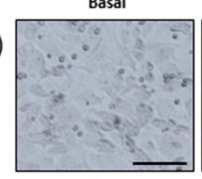

HUVEC
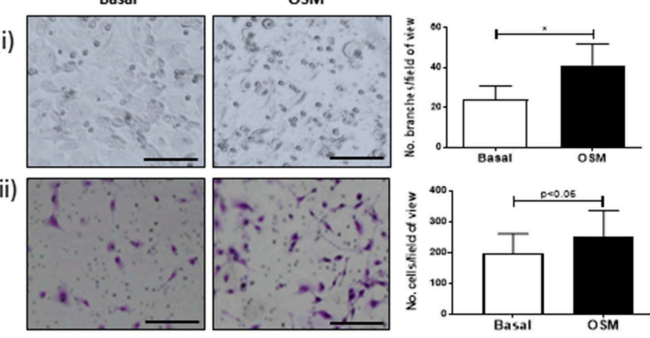

(iii)
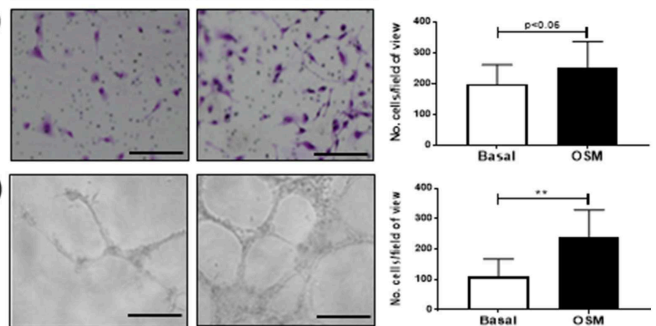

FIGURE 1 | The effect of OSM on cytokine/chemokine secretion, angiogenesis, and cell function in RAFLS and HUVEC. RAFLS and HUVEC were cultured in the presence of OSM (10 ng/ml) for $24 \mathrm{~h}$. (A) Bar graphs demonstrating quantification of IL-6, MCP-1, IL-8, GRO $\alpha$, RANTES secretion in RAFLS ( $n=7-10)$. Gene expression analysis of VEGF, VCAM-1, and ICAM-1 quantified in RAFLS using Real-time PCR. Fold increase compared to endogenous controls (RPLPO and HPRT1) $(n=6-10)$. (B) Bar graphs demonstrating secretion of IL-6, MCP-1, IL-8, GRO $\alpha$, RANTES in HUVEC $(n=6-10)$. Gene expression analysis of VEGF, VCAM-1, and ICAM-1 quantified in HUVEC using Real-time PCR. Fold increase compared to endogenous controls (RPLPO and HPRT1) $(n=4)$. (C) Representative photomicrographs and accompanying bar graphs demonstrating (i) leukocyte adhesion and number of attached cells $(n=5)$, (ii) invasion and number of invading cells $(n=8)$ in RAFLS incubated with OSM for 24 and $48 \mathrm{~h}$, respectively. (D) Representative photomicrographs and accompanying bar graphs demonstrating (i) tubule formation and average number of branches $(n=3)$, (ii) leukocyte adhesion and average number of attached cells $(n=6)$, (iii) invasion and average number of invading cells $(n=4)$ in HUVEC incubated with OSM for $24 \mathrm{~h}$. Values expressed as mean \pm SEM, Wilcoxon signed rank and paired $t$-test were used for RAFLS and HUVEC, respectively. ${ }^{\star} p<0.05,{ }^{* *} p<0.01,{ }^{* \star *} p<0.005$ significantly different from basal.

in the formation of tube-like structures in response to OSM $(p<0.05)$.

\section{OSM Differentially Regulates Cellular Bioenergetics in RAFLS and HUVEC}

To analyse the two major energy pathways, oxidative phosphorylation and glycolysis, in real time the Seahorse XFe-Analyzer was utilized as previously described (29). Supplementary Figures 1A,B demonstrates the average bioenergetic profiles for OCR in RAFLS and HUVEC cells before and after injections of mitochondrial inhibitors; oligomycin, FCCP, and antimycin A in OSM vs. basal control. OSM had no effect on basal respiration in RAFLS, yet increased the maximal respiratory capacity $(p<0.05)$, paralleled by a significant reduction in ATP synthesis $(p<0.05)$ (Supplementary Figures 1A,C). OSM had no effect on the OCR profile of HUVEC (Supplementary Figures 1B,D). This was accompanied by a significant shift to a glycolytic profile of both RAFLS and HUVEC, whereby OSM significantly increased baseline glycolysis $(p<0.05)$ and maximum glycolytic capacity $(p<0.05)$, leading to an overall increase in the ECAR/OCR ratio in favor of glycolysis for both RAFLS and HUVEC (all $p<0.05$ ) (Figures 2A,B). Furthermore, we demonstrated an increase in the glucose transporter GLUT-1 (Figures 2C-F) and in HIF1 $\alpha(p<0.01)$ (Figures 2C,D), a master regulator of cellular and systemic homeostatic responses to hypoxia. This glycolytic shift was further supported by the observed increase in key glycolytic enzymes HK2 $(p<0.05)$ (Figures 2C-F), the first enzyme in the glycolysis pathway, and PFKFB3 $(p<0.01)$ (Figures 2C-F), which catalyzes the conversion of fructose-6phosphate to fructose-2,6-bisP (F2,6BP). F2,6BP is a "potent" allosteric activator of 6-phosphofructokinase-1 (PFK-1) which is one of the rate-limiting enzymes of glycolysis. LDHA and PKM2 expression were also significantly increased in RAFLS in response to OSM, with no effect observed in $\operatorname{HUVEC}(p<0.05)$ (Figures 2C,D).

\section{OSM in Combination With TNF $\alpha$ Differentially Regulates Cytokines and Chemokines in RAFLS and HUVEC}

We have shown that OSM displays differential effects on proinflammatory/angiogenic mediators in RAFLS and HUVEC, and 


\section{RAFLS}

A
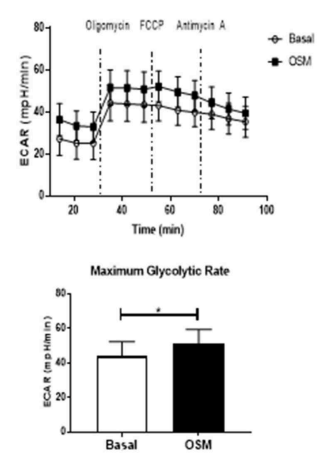

C
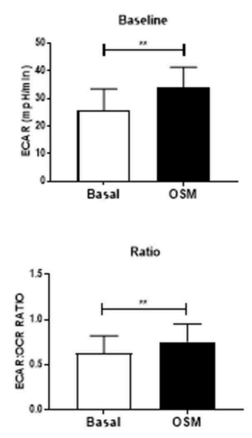

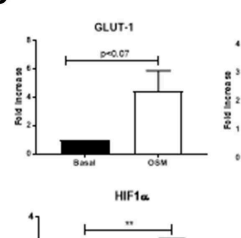

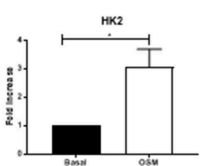

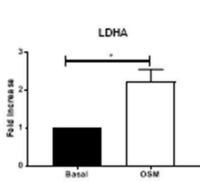

HUVEC
E
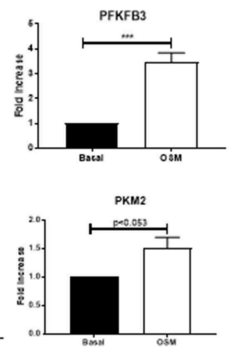

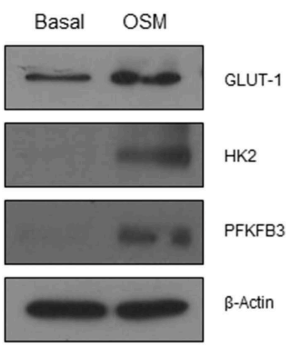

B
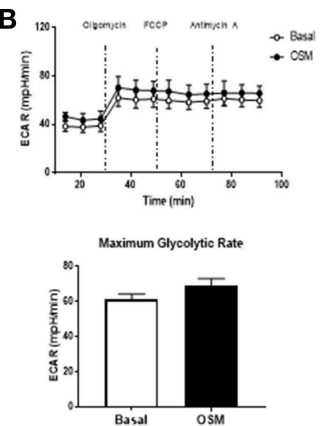
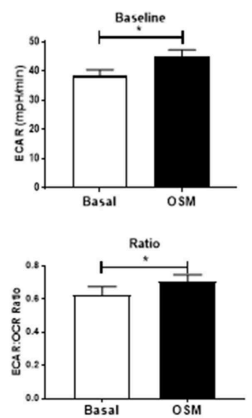
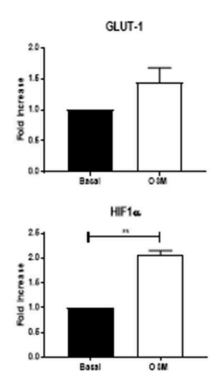

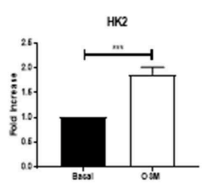

LOHA

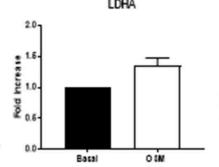

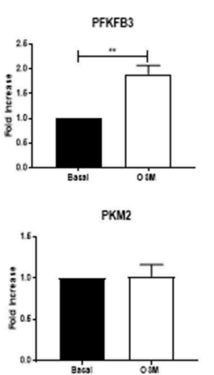

$\mathbf{F}$

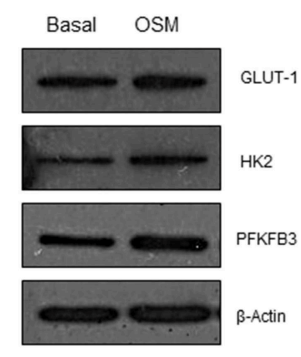

FIGURE 2 | OSM induces glycolytic mechanisms in in RAFLS and HUVEC. Average seahorse profiles demonstrating extracellular acidification rate (ECAR) (glycolysis) in (A) RAFLS ( $n=8)$ and (B) HUVEC $(n=4)$, before and after injections of oligomycin, FCCP, and antimycin A following $3 \mathrm{~h}$ OSM (10 ng/ml) stimulation. Representative bar graphs demonstrating baseline ECAR, maximal glycolytic rate and ECAR:OCR ratio in (A) RAFLS and (B) HUVEC. Representative bar graphs demonstrating mRNA expression of glucose transporter 1 (GLUT-1), hexokinase 2 (HK2), 6-phosphofructo-2-kinase/fructose-2,6-biphosphatase 3 (PFKFB3), HIF1 $\alpha$, lactate dehydrogenase A (LDHA glucose transporter 1 and pyruvate kinase M2 (PKM2) in (C) RAFLS ( $n=5-6)$ and (D) HUVEC ( $n=4-8)$ treated with OSM (10 ng/ml) for $24 \mathrm{~h}$. Fold increase compared to endogenous controls (RPLPO and HPRT1). Representative western blot showing GLUT-1, HK2, PFKFB3 in (E) RAFLS and (F) HUVEC, $\beta$-actin was used as loading control. Wilcoxon signed rank and paired $t$-test were used for RAFLS and HUVEC, respectively. Data expressed as mean \pm SEM, ${ }^{\star} p<0.05,{ }^{\star \star} p<0.01,{ }^{\star \star \star} p<0.005$ significantly different from basal.

shown that in both cell types OSM induces a shift toward glycolysis. Based on previous studies demonstrating the ability of OSM to synergise with other key cytokines within the joint environment, we next examined the effect of OSM in combination with TNF $\alpha$ on these mechanisms. Both RAFLS and HUVEC were cultured with increasing concentrations of $\mathrm{TNF} \alpha$, in the presence or absence of OSM. OSM potentiated the effect of TNF $\alpha$ on both IL-6 $(p<0.05)$ and MCP-1 ( $p$ $<0.05)$ at all concentrations in both RAFLS and HUVEC (Figures 3A,B). In contrast, OSM inhibited the stimulatory effect of TNF $\alpha$ on IL-8 $(p<0.05)$ and GRO $\alpha(p<0.05)$, with the levels of both chemokines significantly reduced in response to OSM + TNF $\alpha$ compared to TNF $\alpha$ alone (Figures 3A,B). Interestingly, OSM alone had no effect on RANTES secretion from both RAFLS and HUVEC, however in combination with $\mathrm{TNF} \alpha$, divergent effects were observed for RAFLS compared to HUVEC. OSM potentiated the effect of TNFa on RANTES secretion $(p<0.05)$ (Figure 3A), however OSM significantly inhibited the effect of TNF $\alpha$ on RANTES in HUVEC $(p<$ 0.05 ) (Figure 3B). These data again show the divergent pro-/antiinflammatory effects of OSM, and its ability to alter the effects of one of the main cytokines that drives inflammation within the RA joint.

\section{OSM in Combination With TNF $\alpha$ Regulates Metabolic Reprogramming in RAFLS, an Effect Mediated Through Phosphorylation of STAT3}

To further explore the synergistic interaction between OSM and $\mathrm{TNF} \alpha$, we next examined their combined effect on cellular metabolism. While OSM had no effect on baseline OCR, TNFa alone significantly reduced baseline OCR ( $p$ $<0.05$ ) (Figures 4A-C), an effect further potentiated with the combination of OSM+TNF $\alpha(p<0.05)$ (Figures $4 \mathrm{~A}-\mathrm{C}$ ). Maximum respiratory capacity was significantly reduced in response to the combination of OSM and TNF $\alpha(p<$ 0.05) (Figure 4B). Furthermore, the cytokines alone and in combination resulted in a stepwise inhibition of ATP synthesis (all $p<0.05$ ) (Figure 4B). In contrast, OSM and TNF $\alpha$ alone and in combination, significantly induced a stepwise progressive increase in baseline glycolysis (all $p<0.05$ ) (Figures 4C,D) and 
A

\section{RAFLS}
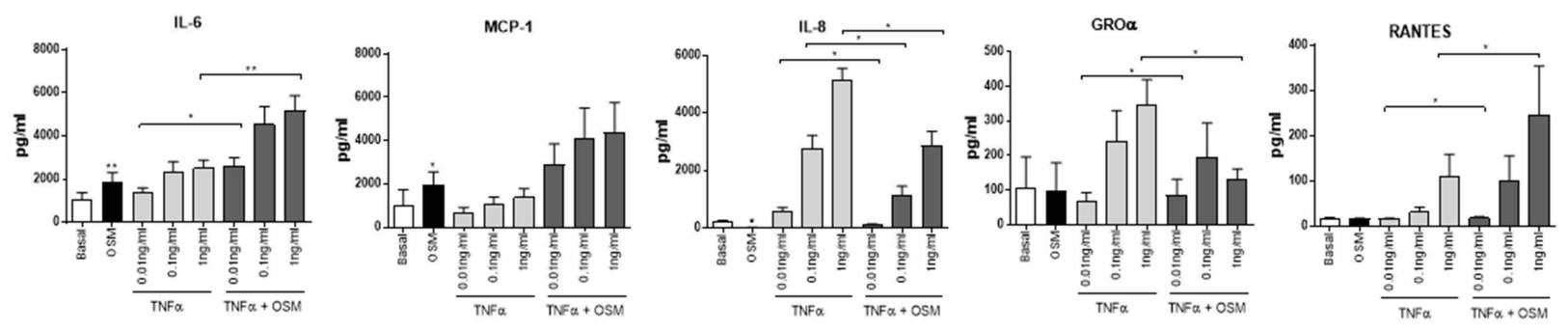

HUVEC

B
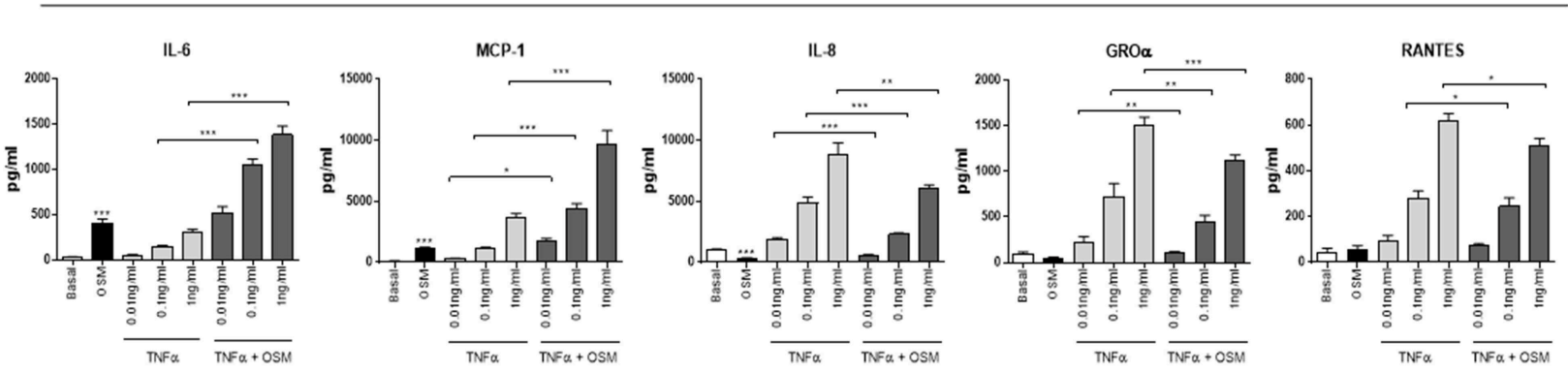

FIGURE 3 | OSM in combination with TNF $\alpha$ regulates cytokine/chemokine secretion in RAFLS and HUVEC. RAFLS and HUVEC were cultured in the presence of $\operatorname{OSM}(10 \mathrm{ng} / \mathrm{ml})$ and increasing concentrations of TNF $\alpha(0.01,0.1,1 \mathrm{ng} / \mathrm{ml})$ for $24 \mathrm{~h}$. Bar graphs showing the measured secretion of IL-6, MCP-1, IL-8, GRO $\alpha$, and RANTES from (A) RAFLS $(n=7-10)$ and (B) HUVEC $(n=10-11)$ following the outlined treatments by ELISA. Values expressed as mean \pm SEM, Wilcoxon signed rank and paired $t$-test were used for RAFLS and HUVEC, respectively. ${ }^{*} p<0.05,{ }^{\star \star} p<0.01,{ }^{* \star *} p<0.005$.

the maximal glycolytic rate (all $p<0.05$ ) (Figures 4C,D). This resulted in an overall significant increase in the ECAR/OCR ratio in response to both OSM $(p<0.05)$ and $\mathrm{TNF} \alpha(p<$ 0.05 ) alone, an effect that was potentiated in response to the combination $(p<0.05)$ (Figure 4E). This metabolic shift was further supported by the increased induction of GLUT-1, HK2 $(p<0.05)$, PFKFB3 $(p<0.05)$, HIF1 $\alpha(p<0.05)$, LDHA $(p$ $<0.05)$, and PKM2 $(p<0.05)$ in response to the combination of OSM+TNF $\alpha$ compared to either cytokine alone (Figure 4F). In contrast, no effect was observed for baseline OCR, maximum respiratory capacity or ATP synthesis in HUVEC in response to OSM + TNF $\alpha$ (Supplementary Figures 2A,B). However, similar to RAFLS, OSM + TNF $\alpha$ induced a significant induction in the glycolytic capacity of HUVEC as demonstrated in the ECAR profiles (Supplementary Figures 2C-E) and in the expression of key glycolytic genes (Supplementary Figure 2F).

The overall metabolic profile of both RAFLS and HUVEC is shown in Figure $\mathbf{5 A}$, where they move toward a more glycolytic/energetic profile in response to the combination of OSM and TNFQ however there are differences in the mechanisms whereby OCR was inhibited in RAFLS, with no effect observed for HUVEC. Therefore, we next assessed their effect on phosphorylation of STAT3, a key component of the JAK-STAT pathway which mediates OSM signaling. In RAFLS, OSM induced STAT3 gene expression $(p<0.05)$ (Figure 5B) and STAT3 phosphorylation (pSTAT3) as observed by western blot (Figure 5C and Supplementary Figure 3). TNF $\alpha$ also induced pSTAT3 but to a lesser extent (Figures 5B-D). Interestingly, the combination of OSM and TNF $\alpha$ in RAFLS significantly induced both gene expression compared to either OSM or TNF $\alpha$ alone (Figure 5B). Furthermore, the combination of OSM and TNF $\alpha$ in RAFLS induced activation of STAT3 (Figure 5C) in two out three RAFLS. In contrast, while OSM induced STAT3 gene expression and protein phosphorylation in HUVEC, the addition of TNF $\alpha$ had no effect either alone or in combination with OSM (Figures 5B,D). This suggests that in RAFLS, OSM, and TNF $\alpha$ have the ability to act together in the activation of STAT3, an effect that does not occur in HUVEC.

\section{DISCUSSION}

OSM is a crucial player in the pathogenesis of RA, however its relative contribution to specific mechanisms involved in synovial inflammation remain to be fully elucidated, primarily due to the pleiotropic nature of this cytokine. In this study we demonstrate that OSM alone differentially regulates proinflammatory mechanisms and significantly promotes proangiogenic and pro-invasive mechanisms in RAFLS and HUVEC. This is accompanied by a change in the cellular bioenergetic profile of the cells, whereby OSM significantly increases the ECAR/OCR ratio in favor of glycolysis, paralleled by the induction of the glucose transporter GLUT-1 and key glycolytic enzymes (HK2, PFKFB3, HIF1 $\alpha$ ). Next, we demonstrate that OSM synergizes with $\mathrm{TNF} \alpha$ to differentially regulate pro-inflammatory mechanisms in RAFLS and HUVEC. Interestingly, OSM synergizes with $\mathrm{TNF} \alpha$ to regulate metabolic 


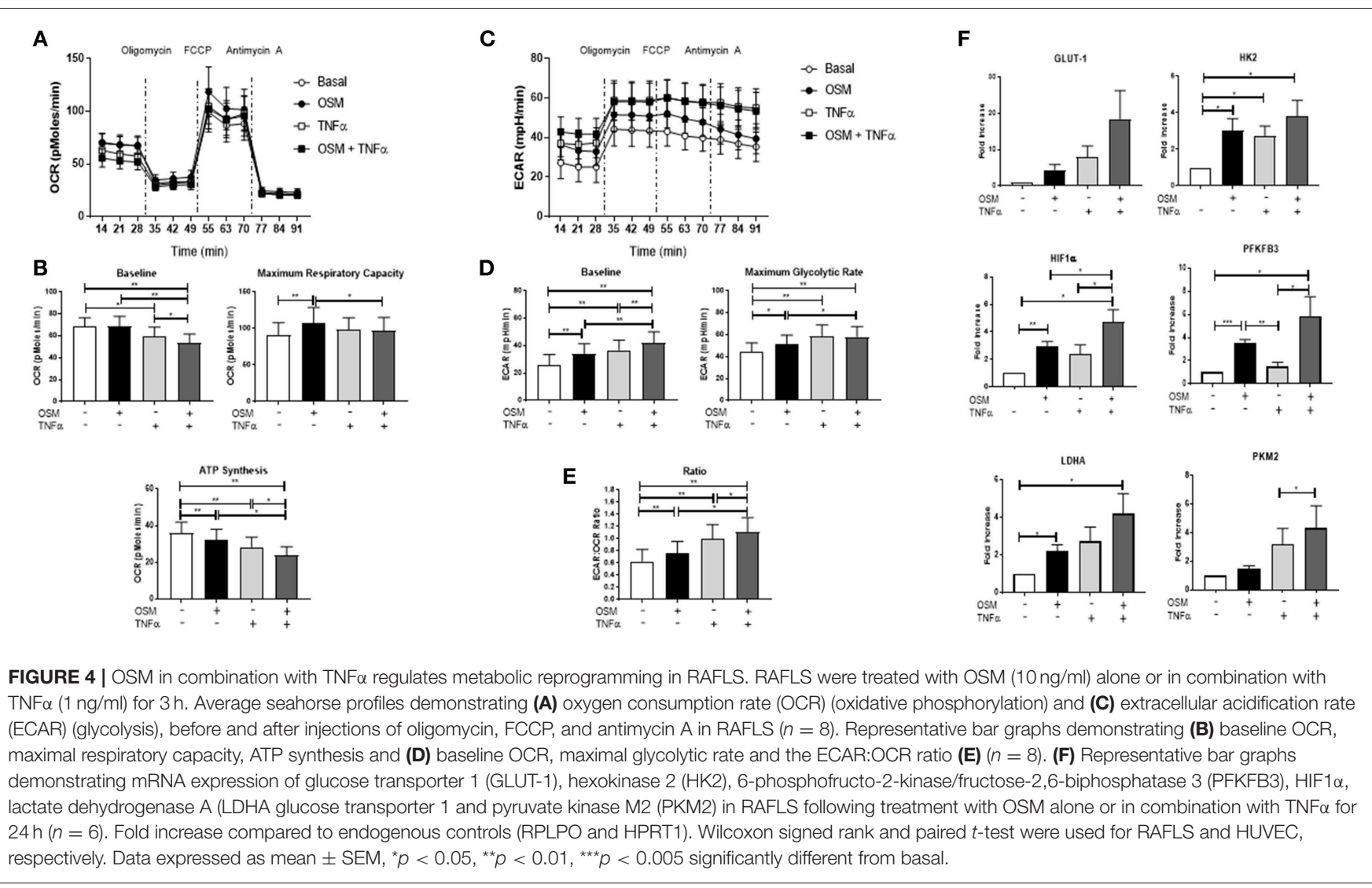

reprogramming, whereby an induction of glycolytic activity with concomitant attenuation of mitochondrial respiration and ATP activity is observed in RAFLS, but not in HUVEC. Finally, we identify that the combination of OSM with TNF $\alpha$ induces transcriptional activity of STAT3 in RAFLS, with no effect observed in HUVEC. Together, this study indicates that OSM is an important player in orchestrating pro-inflammatory, angiogenic and invasive events in RA, specifically in RAFLS, effects that are mediated by interactions with both TNF $\alpha$ and STAT3.

In this study, OSM differentially regulates cytokine and chemokine secretion in both RAFLS and HUVEC, significantly inducing IL-6 and MCP-1, yet inhibiting IL-8 and GRO $\alpha$, with minimal effect observed on RANTES. While this is the first study to demonstrate the opposing action of OSM on these specific cytokine/chemokines in RAFLS and HUVEC, it is consistent with previous studies demonstrating differential effects in other cell types $(33,34)$. Specifically, OSM alone can induce GM-CSF, IL-6, growth factors VEGF and bFGF, the osteoclastogenic cytokine RANKL, and many MMP (24, 35-38). Furthermore, OSM has been shown to differentially regulate chemokines/adhesion molecules, inducing CXCL5, IP10, CCL2, MCP-1, and ICAM-1 in lung fibroblasts, osteoblasts and epithelial cells, with no effect observed for other mediators such as GRO $\alpha$, MIP-1, and VCAM-1 (24). The effect of OSM on chemokine expression has also been observed in mouse models of pneumonia (39), experimental autoimmune encephalomyelitis (EAE), and cancer $(40,41)$.

Furthermore, we demonstrate that OSM promotes proangiogenic mechanisms and leukocyte adhesion, accompanied by induction of VEGF and ICAM-1. VEGF is a pivotal "on" switch for angiogenesis, promoting EC proliferation, migration, and invasion (42-45), with numerous studies demonstrating increased expression of VEGF and its receptors in RA synovial tissue $(42,46,47)$. This is further supported by studies indicating that OSM can have differential effects on angiogenic mechanisms dependent on STAT activation, with pSTAT1 inhibiting VEGF expression, yet pSTAT3 promoting VEGF expression $(48,49)$. The effect of OSM on leukocyte adhesion has also been observed in mouse models of arthritis (50). OSM has also been shown to upregulate the expression of CCL13 in RAFLS (51), to induce key chemokines involved in leukocyte chemotaxis (CXCL3, CCL2, CCL5, CCL20), in addition to promoting infiltration of macrophages and neutrophils in mice models of inflammation (52). The observed differential effects of OSM on VCAM-1 expression again highlights its pleiotropic nature in different cell types, possibly influenced by the inflammatory microenvironment.

These striking changes in cellular function are, in fact, mirrored by distinct alterations in the metabolic profiles of OSM-treated cells, resulting in a shift in the ECAR:OCR ratio in favor of glycolysis. This shift is supported by the observed increase in key glycolytic drivers in response to 
A

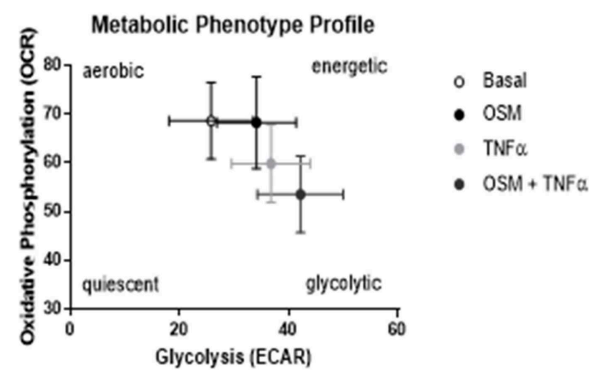

B

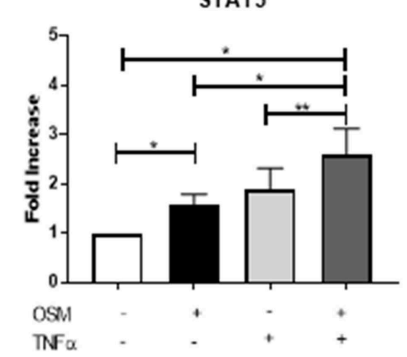

HUVEC

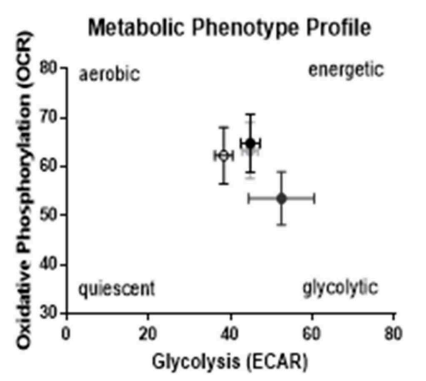

STAT3

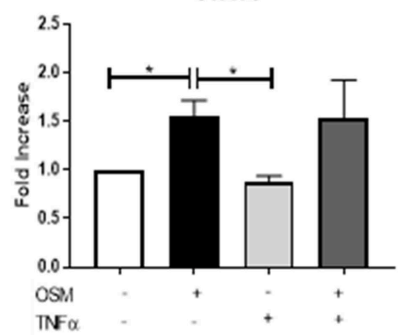

C
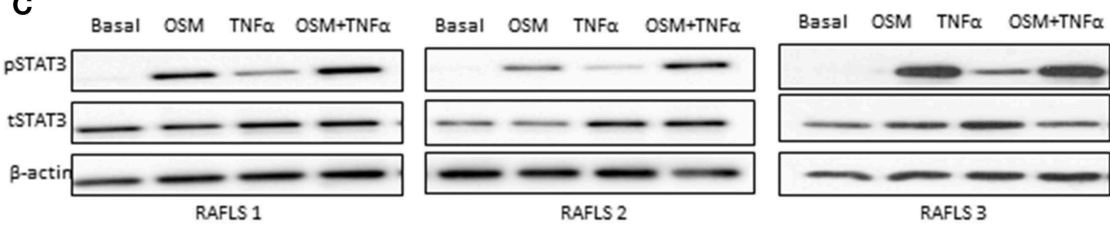

D

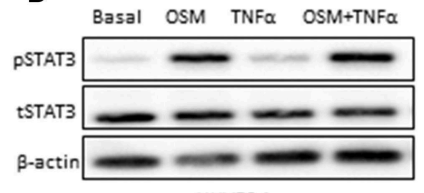

HUVEC 1

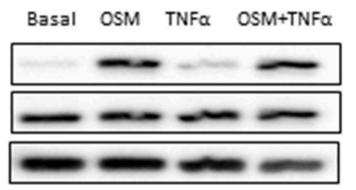

HUVEC 2

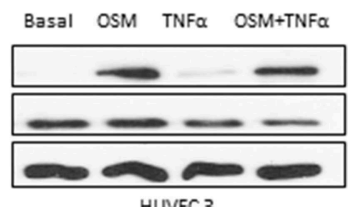

HUVEC 3

FIGURE 5 | OSM in combination TNF $\alpha$ regulates STAT3 expression in RAFLS. (A) Metabolic phenotype profiles in RAFLS and HUVEC representing changes in metabolic phenotype in response to OSM (10 ng/ml) and TNF $\alpha(1 \mathrm{ng} / \mathrm{ml})$ alone and in combination. (B) Representative bar graphs demonstrating mRNA expression of STAT3 in RAFLS $(n=6)$ and HUVEC $(n=4)$ following treatment with OSM alone or in combination with TNF $\alpha$ for 24 h. Fold increase compared to endogenous controls (RPLPO and HPRT1), data analyzed using paired $t$-test. Data expressed as mean \pm SEM, ${ }^{*} p<0.05$, ${ }^{* *} p<0.01$. Representative western blot showing phospho-STAT3 (pSTAT3) and total-STAT3 (tSTAT3) in RAFLS (C) and HUVEC (D). $\beta$-actin was used as loading control.

OSM treatment, where induction of HIF1 $\alpha$, PFKFB3, HK2, LDHA, PKM2, and GLUT-1 was demonstrated. The metabolic switch in HUVEC in response to OSM is consistent with previous studies indicating that active endothelial cells rely heavily on glycolysis. Indeed, $85 \%$ of endothelial cell ATP requirements comes from the conversion of glucose to lactate, mechanisms that are crucial for tip cell formation and blood vessel migration (53-55). This preferential use of glycolysis has also been demonstrated in the inflamed RA joint, with studies showing that glycolytic markers are inversely correlated with synovial $\mathrm{pO}_{2}$ levels $(9,56,57)$. In addition, previous studies have shown that OSM can promote glycolytic mechanisms in human hepatocyte cell lines in a PDK-1-dependent manner and can induce HIF1 $\alpha$ in different cell types to promote tumor progression in cancer cells $(58,59)$. Consistent with the observed increase in PFKFB3 in this study, previous studies have reported that blockade of PFKFB3 inhibits angiogenic tube formation, secretion of pro-inflammatory/angiogenic mediators, and key signaling pathways in both RAFLS and endothelial cells (9). Moreover, blockade of PFKFB3 in animal models of RA, psoriasis and colitis has led to resolution of inflammation $(60,61)$.

The inflamed synovial joint is hallmarked by a complex mixture of pro-inflammatory cytokines and chemokines interacting with each other to promote the inflammatory response. In this study we demonstrate that OSM potentiates the effect of TNF $\alpha$ on IL- 6 and MCP-1 secretion from HUVEC and RAFLS, inhibits TNF $\alpha$-induced IL- 8 and GRO $\alpha$, while displaying differential effects on RANTES, with OSM significantly inhibiting TNF $\alpha$-induced RANTES expression in HUVEC, while potentiating $\mathrm{TNF} \alpha$-induced RANTES in RAFLS. The ability 
of OSM to cooperate with key pro-inflammatory mediators such as IL-1 $\beta$, IL-17, and TNF $\alpha$ has been previously reported $(25,31,62)$. In mouse synovial fibroblasts, OSM augments the effects of TNF $\alpha$ and IL- $1 \beta$ on IL- 6 secretion (38), inhibits IL- $1 \beta$ induced IL-8 and GM-CSF expression (30), and can synergise with TLR-4 to induce MCP-1 in human aortic adventitious fibroblasts and smooth muscle cells (63). Furthermore, OSM inhibits TNF $\alpha$-induced TIMP-1 expression, yet potentiates IL- $1 \beta$-induced TIMP- 1 and MMP- 1 in $\operatorname{RAFLS~}(24,31,64)$.

Interestingly, we identified that the synergistic effects observed with $\mathrm{OSM}$ and $\mathrm{TNF} \alpha$ together also differentially altered the metabolic profile of the cells. Specifically, the combination of $\mathrm{OSM}$ and TNF $\alpha$ reduced the mitochondrial respiration paralleled by a stepwise induction of glycolysis in RAFLS, an effect not observed in HUVEC. Indeed, we demonstrate that the synergy between OSM and TNF $\alpha$ observed in RAFLS may be STAT3dependent, an effect that appears to be specific to RAFLS and not HUVEC. In line with this, studies have demonstrated that $\mathrm{TNF} \alpha$ is capable of indirectly activating the JAK-STAT pathway through induction of type I interferons in RAFLS (65). The mechanisms by which OSM regulates such effects within the inflamed joint however is unclear, yet studies have suggested that differential activation of its receptors gp130/LIF $\alpha$ and gp130/OSM or differential combinations of STATs (whether they form hetero- or homo-dimers) may account for such opposing effects $(16,66)$.

Furthermore, OSM has been shown to regulate STAT1/3 and STAT5/6 in mouse fibroblasts and is also capable of suppressing cell motility via STAT1 activation in lung cancer (67). Conversely, a recent study has demonstrated that murine OSM phosphorylates STAT3 via gp130/LIF activation but not STAT1 causing specific regulation of STAT3 responsive genes in primary osteocytes (68). Indeed, STAT3 itself is capable of interacting with other STATs; STAT1 for example has been demonstrated to exhibit inhibitory effects against STAT3 signaling in a study on esophageal squamous cell carcinoma (69). Thus, a clearer understanding of the various cues directing this complex transcriptional landscape is vitally important.

In this study, we propose that the altered cellular bioenergetics resulting from the synergy between OSM and $\mathrm{TNF} \alpha$ may rely on STAT3 activation in RAFLS. Interactions between STAT3 and metabolic enzymes have also been demonstrated previously whereby blocking PFKFB3 causes inhibition of pSTAT3 expression in RAFLS (9). In cancer cells, STAT3 regulates glycolysis through $\mathrm{HK} 2(70,71)$, and mediates HIF1 $\alpha$ PKM2-interactions (54). Furthermore, STAT3, has been shown to be localized in the mitochondria, can bind to complex I and, in liver and heart cells, is capable of modulating the electron transport chain by altering activities of complex I and II (72). Finally, in the context of the RA joint, STAT3 interacts with various other key signaling molecules including Notch, NF$\kappa \mathrm{B}$, and hypoxia inducible factors (HIF), all of which regulate each other's activation through complex positive and negative feedback loops in the RA joint (73).

In conclusion, we have shown that OSM is capable of driving pro-inflammatory and metabolic changes, implicating it as a crucial cytokine in orchestrating the inflammatory response in rheumatoid arthritis. Moreover, we demonstrate that OSM enhances the destructive effects of TNF $\alpha$, a key pathogenic factor in disease pathogenesis, effects which are mediated through activation of STAT3.

\section{DATA AVAILABILITY}

All datasets generated for this study are included in the manuscript/Supplementary Files.

\section{AUTHOR CONTRIBUTIONS}

$\mathrm{MH}$ designed and performed experiments, analyzed data, and wrote the manuscript. TR, CC, and SA performed experiments. DV recruited the patients and contributed to the discussion. TM and UF supervised the project and co-wrote the manuscript. All authors read, revised, and approved the submitted manuscript.

\section{FUNDING}

This work was supported by the Irish Research Council, Arthritis Ireland, CARD, and Maeve Binchy funding for arthritis research.

\section{SUPPLEMENTARY MATERIAL}

The Supplementary Material for this article can be found online at: https://www.frontiersin.org/articles/10.3389/fimmu. 2019.02056/full\#supplementary-material

Supplementary Figure 1 | OSM has differential effects on mitochondrial respiration in RAFLS and HUVEC. Average seahorse profiles demonstrating oxygen consumption rate (OCR) (oxidative phosphorylation) in (A) RAFLS $(n=8)$ and $(\mathbf{B})$ HUVEC $(n=4)$, before and after injections of oligomycin, FCCP, and antimycin A following $3 \mathrm{~h}$ OSM $(10 \mathrm{ng} / \mathrm{ml})$ stimulation. (C) Representative bar graphs demonstrating baseline OCR, maximal respiratory capacity, and ATP synthesis in RAFLS $(n=8)$. (D) Representative bar graphs demonstrating baseline OCR, maximal respiratory capacity, and ATP synthesis in HUVEC $(n=4)$. Wilcoxon signed rank and paired $t$-test were used for RAFLS and HUVEC, respectively. Data is expressed as mean $\pm \mathrm{SEM},{ }^{* *} p<0.01$ significantly different from basal.

Supplementary Figure 2 | OSM does not synergise with TNF $\alpha$ to regulate metabolic changes in HUVEC. HUVEC were treated with OSM $(10 \mathrm{ng} / \mathrm{ml})$ alone or in combination with $\mathrm{TNF} \alpha(1 \mathrm{ng} / \mathrm{ml})$ for $3 \mathrm{~h}$. Average seahorse profiles demonstrating (A) oxygen consumption rate (OCR) (oxidative phosphorylation) and $\mathbf{( C )}$ extracellular acidification rate (ECAR) (glycolysis), before and after injections of oligomycin, FCCP, and antimycin A $(n=4)$. Representative bar graphs demonstrating (B) baseline OCR, maximum respiratory capacity, ATP synthesis and (D) baseline ECAR, maximal glycolytic rate and (E) ECAR:OCR ratio. (F) Representative bar graphs demonstrating mRNA expression of glucose transporter 1 (GLUT-1), hexokinase 2 (HK2),

6-phosphofructo-2-kinase/fructose-2,6-biphosphatase 3 (PFKFB3), HIF1 $\alpha$, lactate dehydrogenase A LDHA glucose transporter 1 and pyruvate kinase M2 (PKM2) in HUVEC treated with OSM alone or in combination with TNF $\alpha$ for $24 \mathrm{~h}$ $(n=4-5)$. Fold increase compared to endogenous controls (RPLPO and HPRT1). Data analyzed using paired $t$-test, data expressed as mean \pm SEM, ${ }^{*} p<0.05$, $* * p<0.01,{ }^{* * *} p<0.005$ significantly different from basal.

Supplementary Figure 3 | OSM in combination TNF $\alpha$ regulates STAT3 expression. Bar graphs representing densitometry quantification of pSTAT3 normalized to $\beta$-actin in RAFLS (A) and HUVEC (B). Data expressed as mean \pm SEM. 


\section{REFERENCES}

1. McInnes IB, Schett G. Pathogenetic insights from the treatment of rheumatoid arthritis. Lancet. (2017) 389:2328-37. doi: 10.1016/S0140-6736(17)31472-1

2. Ng CT, Biniecka M, Kennedy A, McCormick J, FitzGerald O, Bresnihan B, et al. Synovial tissue hypoxia and inflammation in vivo. Ann Rheum Dis. (2010) 69:1389-95. doi: 10.1136/ard.2009.119776

3. Pugh CW, Ratcliffe PJ. Regulation of angiogenesis by hypoxia: role of the HIF system. Nat Med. (2003) 9:677-84. doi: 10.1038/nm06 03-677

4. Szekanecz Z, Koch AE. Targeting angiogenesis in rheumatoid arthritis. Curr Rheumatol Rev. (2008) 4:298-303. doi: 10.2174/157339708786263942

5. Tas SW, Maracle CX, Balogh E, Szekanecz Z. Targeting of proangiogenic signalling pathways in chronic inflammation. Nat Rev Rheumatol. (2015) 12:111-22. doi: 10.1038/nrrheum.2015.164

6. Fearon U, Canavan M, Biniecka M, Veale DJ. Hypoxia, mitochondrial dysfunction and synovial invasiveness in rheumatoid arthritis. Nat Rev Rheumatol. (2016) 12:385-97. doi: 10.1038/nrrheum.2016.69

7. Fearon U, Hanlon MM, Wade SM, Fletcher JM. Altered metabolic pathways regulate synovial inflammation in rheumatoid arthritis. Clin Exp Immunol. (2018) 197:170-80. doi: 10.1111/cei.13228

8. Weyand CM, Goronzy JJ. Immunometabolism in early and late stages of rheumatoid arthritis. Nat Rev Rheumatol. (2017) 13:1-11. doi: 10.1038/nrrheum.2017.49

9. Biniecka M, Canavan M, McGarry T, Gao W, McCormick J, Cregan S, et al. Dysregulated bioenergetics: a key regulator of joint inflammation. Ann Rheum Dis. (2016) 75:2192-200. doi: 10.1136/annrheumdis-2015-208476

10. Bustamante MF, Garcia-Carbonell R, Whisenant KD, Guma M. Fibroblastlike synoviocyte metabolism in the pathogenesis of rheumatoid arthritis. Arthritis Res Ther. (2017) 19:110. doi: 10.1186/s13075-017-1303-3

11. Kim S, Hwang J, Xuan J, Jung YH, Cha H-S, Kim KH. Global metabolite profiling of synovial fluid for the specific diagnosis of rheumatoid arthritis from other inflammatory arthritis. Bahn Y-S, editor. PLoS ONE. (2014) 9:e97501. doi: 10.1371/journal.pone.0097501

12. Ciurtin C, Cojocaru VM, Miron IM, Preda F, Milicescu M, Bojincă M, et al. Correlation between different components of synovial fluid and pathogenesis of rheumatic diseases. Rom J Intern Med. (2006) 44:171-81.

13. Naughton D, Whelan M, Smith EC, Williams R, Blake DR, Grootveld M. An investigation of the abnormal metabolic status of synovial fluid from patients with rheumatoid arthritis by high field proton nuclear magnetic resonance spectroscopy. FEBS Lett. (1993) 317:135-8. doi: 10.1016/0014-5793(93)81508-W

14. Garcia-Carbonell R, Divakaruni AS, Lodi A, Vicente-Suarez I, Saha A, Cheroutre $\mathrm{H}$, et al. Critical role of glucose metabolism in rheumatoid arthritis fibroblast-like synoviocytes. Arthritis Rheumatol. (2016) 68:1614-26. doi: $10.1002 /$ art. 39608

15. Son H-J, Lee J, Lee S-Y, Kim E-K, Park M-J, Kim K-W, et al. Metformin attenuates experimental autoimmune arthritis through reciprocal regulation of Th17/Treg balance and osteoclastogenesis. Mediators Inflamm. (2014) 2014:1-13. doi: 10.1155/2014/973986

16. Gearing DP, Comeau MR, Friend DJ, Gimpel SD, Thut CJ, McGourty J, et al. The IL-6 signal transducer, gp130: an oncostatin M receptor and affinity converter for the LIF receptor. Science. (1992) 255:1434-7. doi: $10.1126 /$ science. 1542794

17. O'Shea JJ. Jaks, STATs, cytokine signal transduction, and immunoregulation: are we there yet? Immunity. (1997) 7:1-11. doi: 10.1016/S1074-7613(00)80505-1

18. Fossey SL, Bear MD, Kisseberth WC, Pennell M, London CA. Oncostatin M promotes STAT3 activation, VEGF production, and invasion in osteosarcoma cell lines. BMC Cancer. (2011) 11:125. doi: 10.1186/1471-2407-11-125

19. Hurst SM, McLoughlin RM, Monslow J, Owens S, Morgan L, Fuller GM, et al. Secretion of oncostatin $M$ by infiltrating neutrophils: regulation of IL6 and chemokine expression in human mesothelial cells. J Immunol. (2002) 169:5244-51. doi: 10.4049/jimmunol.169.9.5244

20. Hermanns HM. Oncostatin M and interleukin-31: Cytokines, receptors, signal transduction and physiology. Cytokine Growth Factor Rev. (2015) 26:545-58. doi: 10.1016/j.cytogfr.2015.07.006
21. Richards $\mathrm{CD}$. The enigmatic cytokine oncostatin $\mathrm{m}$ and roles in disease. ISRN Inflamm. (2013) 2013:512103. doi: 10.1155/2013/512103

22. West NR, Hegazy AN, Owens BMJ, Bullers SJ, Linggi B, Buonocore S, et al. Oncostatin $\mathrm{M}$ drives intestinal inflammation and predicts response to tumor necrosis factor-neutralizing therapy in patients with inflammatory bowel disease. Nat Med. (2017) 23:579-89. doi: 10.1038/nm.4307

23. Okamoto H, Yamamura M, Morita Y, Harada S, Makino H, Ota Z. The synovial expression and serum levels of interleukin-6, interleukin-11, leukemia inhibitory factor, and oncostatin $\mathrm{M}$ in rheumatoid arthritis. Arthritis Rheum. (1997) 40:1096-105. doi: 10.1002/art.1780400614

24. Fearon U, Mullan R, Markham T, Connolly M, Sullivan S, Poole AR, et al. Oncostatin $\mathrm{M}$ induces angiogenesis and cartilage degradation in rheumatoid arthritis synovial tissue and human cartilage cocultures. Arthritis Rheum. (2006) 54:3152-62. doi: 10.1002/art.22161

25. Hui W, Rowan AD, Richards $\mathrm{CD}$, Cawston TE. Oncostatin $\mathrm{M}$ in combination with tumor necrosis factor? Induces cartilage damage and matrix metalloproteinase expression in vitro and in vivo. Arthritis Rheum. (2003) 48:3404-18. doi: 10.1002/art.11333

26. Plater-Zyberk C, Buckton J, Thompson S, Spaull J, Zanders E, Papworth $\mathrm{J}$, et al. Amelioration of arthritis in two murine models using antibodies to oncostatin M. Arthritis Rheum. (2001) 44:2697-702. doi: 10.1002/15290131(200111)44:11<2697::AID-ART450>3.0.CO;2-\#

27. Kjelgaard-Petersen CF, Sharma N, Kayed A, Karsdal MA, Mobasheri A, Hägglund P, et al. Tofacitinib and TPCA-1 exert chondroprotective effects on extracellular matrix turnover in bovine articular cartilage ex vivo. Biochem Pharmacol. (2018) 165:91-8. doi: 10.1016/j.bcp.2018.07.034

28. Diller M, Hasseli R, Hülser M-L, Aykara I, Frommer K, Rehart S, et al. Targeting activated synovial fibroblasts in rheumatoid arthritis by peficitinib. Front Immunol. (2019) 10:541. doi: 10.3389/fimmu.2019.00541

29. McGarry T, Orr C, Wade S, Biniecka M, Wade S, Gallagher L, et al. JAK I STAT blockade alters synovial bioenergetics, mitochondrial function, and proinflammatory mediators in rheumatoid arthritis. Arthritis Rheumatol. (2018) 70:1959-70. doi: 10.1002/art.40569

30. Richards CD, Langdon C, Botelho F, Brown TJ, Agro A. Oncostatin $\mathrm{M}$ inhibits IL-1-induced expression of IL-8 and granulocyte-macrophage colony-stimulating factor by synovial and lung fibroblasts. I Immunol. (1996) 156:343-9.

31. Moran EM, Mullan R, McCormick J, Connolly M, Sullivan O, Fitzgerald O, et al. Human rheumatoid arthritis tissue production of IL-17A drives matrix and cartilage degradation: synergy with tumour necrosis factor-alpha, Oncostatin M and response to biologic therapies. Arthritis Res Ther. (2009) 11:R113. doi: 10.1186/ar2772

32. Son H-J, Lee SH, Lee S-Y, Kim E-K, Yang E-J, Kim J-K, et al. Oncostatin M suppresses activation of IL-17/Th17 via SOCS3 regulation in CD4 + T cells. $J$ Immunol. (2017) 198:1484-91. doi: 10.4049/jimmunol.1502314

33. Dayer JM, Burger D. Interleukin-1, tumor necrosis factor and their specific inhibitors. Eur Cytokine Netw. (1994) 5:563-71.

34. Dumas A, Lagarde S, Laflamme C, Pouliot M. Oncostatin M decreases interleukin-1 $\beta$ secretion by human synovial fibroblasts and attenuates an acute inflammatory reaction in vivo. J Cell Mol Med. (2012) 16:1274-85. doi: 10.1111/j.1582-4934.2011.01412.x

35. Yao L, Pan J, Setiadi H, Patel KD, McEver RP. Interleukin 4 or oncostatin $\mathrm{M}$ induces a prolonged increase in P-selectin mRNA and protein in human endothelial cells. J Exp Med. (1996) 184:81-92. doi: 10.1084/jem.184.1.81

36. Vasse M, Pourtau J, Trochon V, Muraine M, Vannier JP, Lu H, et al. Oncostatin $\mathrm{M}$ induces angiogenesis in vitro and in vivo. Arterioscler Thromb Vasc Biol. (1999) 19:1835-42. doi: 10.1161/01.ATV.19.8.1835

37. Faffe DS, Flynt L, Mellema M, Whitehead TR, Bourgeois K, Panettieri RA, et al. Oncostatin M causes VEGF release from human airway smooth muscle: synergy with IL-1 $\beta$. Am J Physiol Cell Mol Physiol. (2005) 288:L1040-8. doi: 10.1152/ajplung.00333.2004

38. Le Goff B, Singbrant S, Tonkin BA, Martin TJ, Romas E, Sims $\mathrm{NA}$, et al. Oncostatin $\mathrm{M}$ acting via OSMR, augments the actions of IL-1 and TNF in synovial fibroblasts. Cytokine. (2014) 68:101-9. doi: 10.1016/j.cyto.2014.04.001

39. Traber KE, Hilliard KL, Allen E, Wasserman GA, Yamamoto K, Jones MR, et al. Induction of STAT3-dependent CXCL5 expression and neutrophil 
recruitment by oncostatin-M during Pneumonia. Am J Respir Cell Mol Biol. (2015) 53:479-88. doi: 10.1165/rcmb.2014-0342OC

40. Sugaya M, Fang L, Cardones AR, Kakinuma T, Jaber SH, Blauvelt A, et al. Oncostatin M enhances CCL21 expression by microvascular endothelial cells and increases the efficiency of dendritic cell trafficking to lymph nodes. $J$ Immunol. (2006) 177:7665-72. doi: 10.4049/jimmunol.177.11.7665

41. Meares GP, Liu Y, Rajbhandari R, Qin H, Nozell SE, Mobley JA, et al, PERK-dependent activation of JAK1 and STAT3 contributes to endoplasmic reticulum stress-induced inflammation. Mol Cell Biol. (2014) 34:3911-25. doi: 10.1128/MCB.00980-14

42. Koch AE, Harlow LA, Haines GK, Amento EP, Unemori EN, Wong WL, et al. Vascular endothelial growth factor. A cytokine modulating endothelial function in rheumatoid arthritis. J Immunol. (1994) 152:4149-56.

43. Ferrara N, Davis-Smyth T. The biology of vascular endothelial growth factor. Endocr Rev. (1997) 18:4-25. doi: 10.1210/edrv.18.1.0287

44. Koch AE. Angiogenesis as a target in rheumatoid arthritis. Ann Rheum Dis. (2003) 62 (Suppl 2):ii60-7. doi: 10.1136/ard.62.suppl _2.ii60

45. DVORAK HF. Angiogenesis: update 2005. J Thromb Haemost. (2005) 3:183542. doi: 10.1111/j.1538-7836.2005.01361.x

46. Fearon U, Griosios K, Fraser A, Reece R, Emery P, Jones PF, et al. Angiopoietins, growth factors, and vascular morphology in early arthritis. $J$ Rheumatol. (2003) 30:260-8.

47. Salvador G, Sanmartí R, Gil-Torregrosa B, García-Peiró A, RodríguezCros JR, Cañete JD. Synovial vascular patterns and angiogenic factors expression in synovial tissue and serum of patients with rheumatoid arthritis. Rheumatology. (2006) 45:966-71. doi: 10.1093/rheumatologykel043

48. Rychli K, Kaun C, Hohensinner PJ, Rega G, Pfaffenberger S, Vyskocil E, et al. The inflammatory mediator oncostatin $\mathrm{M}$ induces angiopoietin 2 expression in endothelial cells in vitro and in vivo. J Thromb Haemost. (2010) 8:596-604. doi: $10.1111 / j .1538-7836.2010 .03741 . x$

49. Albasanz-Puig A, Murray J, Namekata M, Wijelath ES. Opposing roles of STAT-1 and STAT-3 in regulating vascular endothelial growth factor expression in vascular smooth muscle cells. Biochem Biophys Res Commun. (2012) 428:179-84. doi: 10.1016/j.bbrc.2012.10.037

50. Bell MC, Carroll GJ, Chapman HM, Mills JN, Hui W. Oncostatin M induces leukocyte infiltration and cartilage proteoglycan degradation in vivo in goat joints. Arthritis Rheum. (1999) 42:2543-51. doi: 10.1002/15290131(199912)42:12<2543::AID-ANR6>3.0.CO;2-W

51. Hintzen C, Quaiser S, Pap T, Heinrich PC, Hermanns HM. Induction of CCL13 expression in synovial fibroblasts highlights a significant role of oncostatin M in rheumatoid arthritis. Arthritis Rheum. (2009) 60:1932-43. doi: $10.1002 /$ art. 24602

52. Pohin M, Guesdon W, Mekouo AAT, Rabeony H, Paris I, Atanassov H, et al. Oncostatin $\mathrm{M}$ overexpression induces skin inflammation but is not required in the mouse model of imiquimod-induced psoriasis-like inflammation. Eur $J$ Immunol. (2016) 46:1737-51. doi: 10.1002/eji.201546216

53. Eelen G, de Zeeuw P, Treps L, Harjes U, Wong BW, Carmeliet P. Endothelial cell metabolism. Physiol Rev. (2018) 98:3-58. doi: 10.1152/physrev.00001.2017

54. Gao X, Wang H, Yang JJ, Chen J, Jie J, Li L, et al. Reciprocal regulation of protein kinase and pyruvate kinase activities of pyruvate kinase M2 by growth signals. J Biol Chem. (2013) 288:15971-9. doi: 10.1074/jbc.M112. 448753

55. Stapor P, Wang X, Goveia J, Moens S, Carmeliet P. Angiogenesis revisited role and therapeutic potential of targeting endothelial metabolism. J Cell Sci. (2014) 127:4331-41. doi: $10.1242 /$ jcs. 153908

56. Kennedy A, Ng CT, Biniecka M, Saber T, Taylor C, O'Sullivan J, et al. Angiogenesis and blood vessel stability in inflammatory arthritis. Arthritis Rheum. (2010) 62:711-21. doi: 10.1002/art.27287

57. Balogh E, Veale DJ, McGarry T, Orr C, Szekanecz Z, Ng C-T, et al. Oxidative stress impairs energy metabolism in primary cells and synovial tissue of patients with rheumatoid arthritis. Arthritis Res Ther. (2018) 20:95. doi: 10.1186/s13075-018-1592-1

58. Battello N, Zimmer AD, Goebel C, Dong X, Behrmann I, Haan C, et al. The role of HIF-1 in oncostatin M-dependent metabolic reprogramming of hepatic cells. Cancer Metab. (2016) 4:3. doi: 10.1186/s40170-016-0141-0

59. Shrivastava R, Singh V, Asif M, Negi MPS, Bhadauria S. Oncostatin M upregulates HIF- $1 \alpha$ in breast tumor associated macrophages independent of intracellular oxygen concentration. Life Sci. (2018) 194:59-66. doi: $10.1016 /$ j.lfs.2017.12.017

60. Schoors S, De Bock K, Cantelmo AR, Georgiadou M, Ghesquière B, Cauwenberghs S, et al. Partial and transient reduction of glycolysis by PFKFB3 blockade reduces pathological angiogenesis. Cell Metab. (2014) 19:37-48. doi: 10.1016/j.cmet.2013.11.008

61. Zou Y, Zeng S, Huang M, Qiu Q, Xiao Y, Shi M, et al. Inhibition of 6-phosphofructo-2-kinase suppresses fibroblast-like synoviocytes-mediated synovial inflammation and joint destruction in rheumatoid arthritis. $\mathrm{Br} \mathrm{J}$ Pharmacol. (2017) 174:893-908. doi: 10.1111/bph.13762

62. Barksby HE, Hui W, Wappler I, Peters HH, Milner JM, Richards CD, et al. Interleukin-1 in combination with oncostatin $\mathrm{M}$ up-regulates multiple genes in chondrocytes: Implications for cartilage destruction and repair. Arthritis Rheum. (2006) 54:540-50. doi: 10.1002/art.21574

63. Schnittker D, Kwofie K, Ashkar A, Trigatti B, Richards CD. Oncostatin M and TLR-4 ligand synergize to induce MCP-1, IL-6, and VEGF in human aortic adventitial fibroblasts and smooth muscle cells. Mediat Inflamm. (2013) 2013:317503. doi: 10.1155/2013/317503

64. Cawston TE, Curry VA, Summers CA, Clark IM, Riley GP, Life PF, et al. The role of oncostatin $\mathrm{M}$ in animal and human connective tissue collagen turnover and its localization within the rheumatoid joint. Arthritis Rheum. (1998) 41:1760-71. doi: 10.1002/1529-0131(199810)41:10<1760::AID-ART8>3.0. CO;2-M

65. Rosengren S, Corr M, Firestein GS, Boyle DL. The JAK inhibitor CP-690,550 (tofacitinib) inhibits TNF-induced chemokine expression in fibroblast-like synoviocytes: autocrine role of type I interferon. Ann Rheum Dis. (2012) 71:440-7. doi: 10.1136/ard.2011.150284

66. Stahl N, Yancopoulos GD. The alphas, betas, and kinases of cytokine receptor complexes. Cell. (1993) 74:587-90. doi: 10.1016/0092-8674(93)90506-L

67. Pan C-M, Wang M-L, Chiou S-H, Chen H-Y, Wu C-W. Oncostatin M suppresses metastasis of lung adenocarcinoma by inhibiting SLUG expression through coordination of STATs and PIASs signalings. Oncotarget. (2016) 7:60395-406. doi: 10.18632/oncotarget.10939

68. Walker EC, Johnson RW, Hu Y, Brennan HJ, Poulton IJ, Zhang J-G, et al. Murine Oncostatin $M$ acts via leukemia inhibitory factor receptor to phosphorylate Signal Transducer and Activator of Transcription 3 (STAT3) but not STAT1, an effect that protects bone mass. J Biol Chem. (2016) 291:21703-16. doi: 10.1074/jbc.M116.748483

69. Liu Z, Zhang Y, Chen Y, Lin Y, Lin Z, Wang H. STAT1 inhibits STAT3 activation in esophageal squamous cell carcinoma. Cancer Manag Res. (2018) 10:6517-23. doi: 10.2147/CMAR.S182105

70. Okano T, Saegusa J, Nishimura K, Takahashi S, Sendo S, Ueda Y, et al. 3bromopyruvate ameliorate autoimmune arthritis by modulating Th17/Treg cell differentiation and suppressing dendritic cell activation. Sci Rep. (2017) 7:42412. doi: $10.1038 /$ srep 42412

71. Li M, Jin R, Wang W, Zhang T, Sang J, Li N, et al. STAT3 regulates glycolysis via targeting hexokinase 2 in hepatocellular carcinoma cells. Oncotarget. (2017) 8:24777-84. doi: 10.18632/oncotarget.15801

72. Shi LZ, Wang R, Huang G, Vogel P, Neale G, Green DR, et al. HIFlalphadependent glycolytic pathway orchestrates a metabolic checkpoint for the differentiation of TH17 and Treg cells. J Exp Med. (2011) 208:1367-76. doi: $10.1084 /$ jem. 20110278

73. Gao W, McCormick J, Connolly M, Balogh E, Veale DJ, Fearon U. Hypoxia and STAT3 signalling interactions regulate pro-inflammatory pathways in rheumatoid arthritis. Ann Rheum Dis. (2015) 74:1275-83. doi: 10.1136/annrheumdis-2013-204105

Conflict of Interest Statement: The authors declare that the research was conducted in the absence of any commercial or financial relationships that could be construed as a potential conflict of interest.

Copyright $\odot 2019$ Hanlon, Rakovich, Cunningham, Ansboro, Veale, Fearon and McGarry. This is an open-access article distributed under the terms of the Creative Commons Attribution License (CC BY). The use, distribution or reproduction in other forums is permitted, provided the original author(s) and the copyright owner(s) are credited and that the original publication in this journal is cited, in accordance with accepted academic practice. No use, distribution or reproduction is permitted which does not comply with these terms. 